\title{
Validating the Material Values Scale for Children (MVS-c) for Use in Early Childhood
}

\author{
Heleen van der Meulen ${ }^{1} \cdot$ Rinaldo Kühne ${ }^{2}$. \\ Suzanna J. Opree ${ }^{3}$
}

Accepted: 13 February 2017 / Published online: 6 March 2017

(C) The Author(s) 2017. This article is published with open access at Springerlink.com

\begin{abstract}
This study aims to validate the Material Values Scale for children (MVS-c) by Opree et al. (Personality and Individual Differences, 51(8), 963-968, 2011) among children in early childhood. The MVS-c was originally developed to assess materialism among children between the ages of eight to eleven, and consists of three subscales measuring material centrality, material happiness, and material success. We administered the MVS-c to a sample of 120 elementary school children between the ages of six to eight. The MVS-c was presented orally in a structured interview and with the aid of visual response options. We examined the factorial structure, reliability, and construct validity of the full-length 18-item scale as well as the shorter 6- and 3-item versions. Analyses using structural equation modeling showed that its factorial structure (i.e., with material centrality, material happiness and material success as first-order factors and overall material values as a second order factor) holds for younger children. Though the 3-item MVS-c cannot be used among six- to eight-year-olds, the 18-item MVS-c and the shorter 6-item version proved to be both reliable and valid in this age group. Hence, the MVS-c can be used to assess young children's materialism, to examine differences in materialism across developmental phases, and to study developments in children's materialism over time.
\end{abstract}

Keywords Materialism $\cdot$ Children $\cdot$ Early childhood $\cdot$ Scale validation $\cdot$ Structural equation modeling

Suzanna J. Opree

opree@eshcc.eur.nl

1 Communication Analytics, Johan van Hasseltweg 39A, 1021 KNAmsterdam, The Netherlands

2 Department of Communication Science, University of Amsterdam, P.O. Box 15791, 1001 NGAmsterdam, The Netherlands

3 Department of Media and Communication, Erasmus University Rotterdam, P.O. Box 1738, 3000 DRRotterdam, The Netherlands 


\section{Introduction}

The amount of child-directed marketing has increased strongly over the last decades (Kasser and Linn 2016; Mau et al. 2014; Valkenburg 2008). Children's advertising exposure is higher than ever before, amplifying concerns about the commercial pressure placed on children and about the potential negative effects of advertising (Buijzen and Valkenburg 2005). Advertising is known to have many undesirable outcomes for children such as dissatisfaction, unhappiness, parent child conflict, or even aggressive behaviour (Kasser and Linn 2016). One of the main concerns among parents and caretakers as well as academics, though, is that exposure to advertising enhances children's materialism (John 1999; Opree et al. 2014; Vandana and Lenka 2014). Therefore, it is of great relevance to study materialism among children. In order to do this, a proper measurement instrument is essential.

Research has shown that not only children in middle childhood, but even children in early childhood may value the possession of material goods (Goldberg and Gorn 1978; John 1999). Although John's (1999) theory about consumer socialization suggested that children under eight years old evaluate material goods based on perceptual features such as quantity or size only, Chan (2003) found that they actually have an understanding of the value of possessions based on social significance. While younger children in particular are deemed more susceptible to the influence of advertising (Buijzen et al. 2010; Preston 2004), the effect of advertising on their material values has not been studied before. For this reason, it is crucial to study materialism as a result of advertising exposure among younger children. However, measuring this intricate concept among children in early childhood requires an age-appropriate measurement instrument.

Chaplin and John (2007) have taken the first step in finding an age-appropriate instrument by using collages to measure materialism among children in early childhood. Although this method proved to be successful in their study, collage construction might not be the most time-efficient way to measure materialism in children. Using time-efficient measurement tools is particularly important when doing research with young children because of their limited attention span (Borgers et al. 2000). Using time-efficient measurements allows researchers to include additional constructs in their study. Another weakness of the collage measurement is that it is difficult to compare to other measures of materialism, because it does not account for the different dimensions of the construct, whereas other measures of materialism do.

Up until now a valid measurement scale to examine materialism in young children has been missing. Although several measurement scales were developed to measure the construct among older children and adolescents (e.g., Bottomley et al. 2010; Kasser 2005; Opree et al. 2011), none of them were properly tested for use among children in early childhood. Opree et al. (2011) developed the Material Values Scale for children (MVS-c) that measures the three dimensions of materialism suggested by Richins and Dawson (1992) (i.e., material centrality, material happiness, and material success). The MVS-c has, however, only been validated among children between eight and eleven years old. Subsequently, the current study aims to take the next step by validating this scale among children in early childhood.

There are three main advantages of the MVS-c over the collage measurement. Firstly, the close-ended scale is more time-efficient than the collage while measuring 
young children's materialism. Secondly, the MVS-c is more detailed than the collage, as it differentiates the three dimensions of materialism proposed by Richins and Dawson (1992), whereas the collage does not. Thirdly, the MVS-c allows for accurate comparisons between age groups, in contrast to the collage which has to be adopted to each specific age group. The goal of this study is to validate the MVS-c by Opree et al. (2011) for the use among children in early childhood (ages six to eight). Specifically, this study will test the factorial structure of the full-length scale to find out whether its presumed second-order structure also holds for younger children, examine the reliability and construct validity of the full-length MVS-c, and examine the reliability and construct validity of the two shorter versions (i.e., with 6 and 3 items).

\subsection{The MVS-c}

The Material Values Scale for children (MVS-c) was developed by Opree and colleagues in 2011. The scale was based on Richins and Dawson's (1992) Material Values Scale (MVS) which measures materialism among adults by means of three subscales. According to Richins and Dawson (1992) materialistic values encompass three different dimensions: the centrality of possessions and their acquisition in a person's life (i.e., material centrality), the belief that possessions and their acquisition are essential to one's happiness and life satisfaction (i.e., material happiness), and the use of possessions in judging the success of others and oneself (i.e., material success). Hence, the MVS treats materialism as a second-order construct and material centrality, material happiness, and material success as underlying first-order constructs.

Likewise, the MVS-c (Opree et al. 2011) aims to measure materialism among children through material centrality, material happiness, and material success. Just as the original MVS, the scale consists of three subscales including six items each. The original 18 MVS items were adjusted to make them more appropriate for use among children. All items of the MVS-c were formulated in a clear language and address types of possessions that are relevant in children's lives (Opree et al. 2011). Furthermore, the number of response options was reduced from five to four, because neutral response options need to be avoided in research among children; children have difficulty distinguishing a difference in meaning between options when six or more are used (Borgers et al. 2004). The MVS-c was proven valid and reliable in measuring materialism among eight- to eleven-year-olds.

The original MVS-c authors also tested two shorter versions of the scale. Because children in this age group still have a short attention span and quickly loose interest (Borgers et al. 2000), shorter measurement scales are usually preferred. A 6-item version and a 3-item version of the MVS-c were created, which assessed the three dimensions of materialism with two indicators and one indicator for each dimension, respectively. The shorter versions of the MVS-c performed just as well as the fulllength scale in terms of reliability and validity (Opree et al. 2011).

\subsection{Adapting the MVS-c to Younger Children}

To be able to use the MVS-c to measure materialism among a younger age group, such as children in early childhood (ages 6 to 8 ), some adaptions had to be made first. To start, the mode of administration had to be changed. Among older children or 
adolescents, the MVS-c can be employed as a self-administered questionnaire. However, because children under eight are limited in their language development (Borgers et al. 2000), self-administered questionnaires are not suited for this age group. Due to the low or even lacking reading skills of children in early childhood, it is required to read the questions out loud to the children. This means that the MVS-c had to be administered orally. Because young children are very suggestible and often reluctant to express their own thoughts or feelings in surveys (Borgers et al. 2000), the MVS-c needs to be administrated to children individually in order to prevent them from being influenced by their peers or feeling uncomfortable when answering the questions. Hence, the preferred way to administrate the MVS-c to children in early childhood is in an individual structured interview.

Not only the mode of administrating the questions needed to be changed, the same was true for the response options. Because children under eight still have limited verbal memory (Borgers et al. 2000), it is difficult for them to retrieve response options if they are presented orally. To avoid this issue, cards with visual representations of the response options can be used (Greig et al. 2007). For the MVS-c, we replaced the verbal response options of the scale by visual response options with verbal labels. The response options (1) "no, not at all," (2) "no, not really," (3) “yes, a little," and (4) "yes, very much" were represented by (1) a very unhappy smiley, (2) a slightly unhappy smiley, (3) a slightly happy smiley and (4) a very happy smiley. So-called smiley scales have been used to measure children's attitudes in many different contexts. The use of smiley scales has been validated by Reynolds-Keefer et al. (2009), who found that there is no difference in variability in scores between children in early childhood who have been presented with verbal response options (yes/no) and children who were presented with a pictorial Likert scale.

\subsection{Validating the MVS-c}

The present study aims to validate the MVS-c among children between six and eight years of age. For this purpose the factorial structure of the scale will be tested first. Following Richins and Dawson's (1992) seminal conceptualization of materialism as a three-dimensional concept (see also Opree et al. 2011), a second-order structure with overall materialism as second-order construct and material centrality, material happiness, and material success as first-order factors is presumed (see Fig. 1). After this, scales will be created for the three dimensions as well as the 6-item and 3-item short scale. The scales will be subjected to reliability tests, and used to assess the construct validity of the MVS-c among this age group. Reliability assesses whether children's responses across the items are consistent and can be tested by calculating Cronbach's alpha (Kline 2008). Construct validity refers to whether the scale measures what it was designed to measure (Kline 2008; Noar 2003) and can be assessed by examining to what extent the MVS-c correlates with other measures of the same construct and variables known to be related to the construct (Noar 2003).

To provide evidence for the construct validity of the MVS-c among six- to eightyear-olds, the scale will be compared to the previously used measurement instrument of children's level of materialism, that is, the collage measure of Chaplin and John (2007). Children's MVS-c scores are believed to be correlated to the outcomes of the collage method as well as several other variables that have been associated with materialism, 


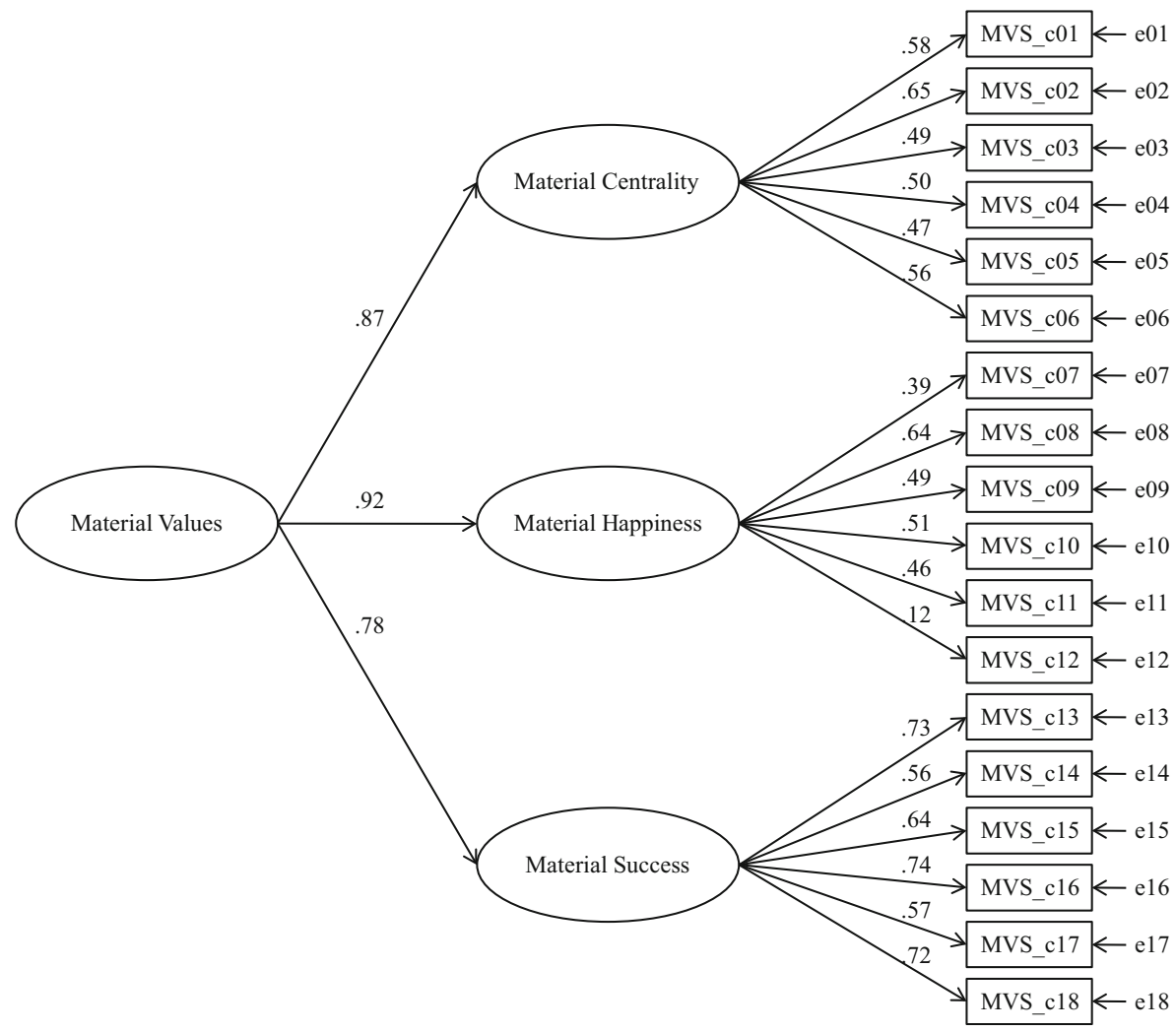

Fig. 1 Second-order factor model of the 18-item MVS-c with material centrality, material happiness, and material success as first-order factors. All factor loadings are standardized

namely gender, advertising exposure, requests to parents for products seen on TV, and life satisfaction. In previous studies, gender differences in materialism have been observed, with boys being somewhat more materialistic than girls (Goldberg et al. 2003; John 1999; Kasser 2005). In addition, children who were frequently exposed to advertising, appeared to be more materialistic than children who were less frequently exposed to advertising (Buijzen and Valkenburg 2003a; Buijzen and Valkenburg 2003b; Opree et al. 2011). Goldberg et al. (2003) found that materialistic children, more often than less materialistic children, asked their parents to buy a product that they had seen on TV. Lastly, life satisfaction was negatively related to materialism (Kasser 2005; Opree et al. 2012): Children who were less satisfied with their life tended to be more materialistic than other children.

\section{Method}

\subsection{Sample}

Two elementary schools in the western part of the Netherlands cooperated in the study and a total of 125 of their pupils participated in the study. Prior to the study, all parents 
of children in the third and fourth grade (equivalent to first and second grade in the American school system) received an informed consent letter. The letter provided detailed information about the study and its procedure and enabled parents to withdraw their permission if they did not want their child to participate. The study was granted IRB-approval by the university's ethical committee. To make sure that only children with valid scores on the main variable of interest (i.e., on the MVS-c) were included in the sample, five children who had missing values on the MVS-c were removed from the sample. The final sample consisted of 57 boys (27 3rd-graders, 304 th-graders) and 63 girls (31 3rd-graders, 32 4th-graders) in the ages of six to eight $(M=6.99, S D=.82)$.

\subsection{Procedure}

A female interviewer guided the children throughout the study. She first explained the collage construction task and supervised the child in the construction process. Then, in the structured interview, all questions and response options of the MVS-c and other measures were read out loud and visual representations of the response options were provided whenever children had to choose from a response scale (Greig et al. 2007). The collage was constructed first in order to avoid priming effects. Had the children answered the questions of the MVS-c scale first, this could have primed thoughts about possessions and consumption and, ultimately, result in children picking more material goods to include in their collage than they would have otherwise. The children with parental permission and who also wanted to participate in the study themselves, were picked up from the classroom and accompanied to another room. The room where the study took place was quiet and somewhat smaller than a classroom. In the room, there was a table where the child and the interviewer could sit opposite to each other. On a second table, the collage board and materials were laid out. After the researcher introduced herself, the children were told that they were going to complete a small task that had to do with the magnetic board and that they had to answer a couple of questions. It was emphasized by the researcher that the children could say anything they wanted during the interview, that there were no wrong answers, and that their responses would not be disclosed to other children or people. Also, children were informed that they could stop participating at any time.

To familiarize the children with the setting and make them feel at ease, the interviewer first asked a series of simple questions regarding the child's gender, age, and grade level. After this, the child was instructed to construct a collage of items that made him or her happy, using the provided materials. Children could take as long as they needed for this task. The study continued with a number of questions about television viewing, asking parents for products seen on TV, children's material values, and their life satisfaction. Lastly, the children indicated if they enjoyed participating in the study and whether they thought participating was easy difficult. Afterwards the children were thanked and accompanied to their classroom. The whole procedure took about 15 to $20 \mathrm{~min}$ per child.

\subsection{Measures}

MVS-c The Material Values Scale for children by Opree et al. (2011) consisted of 18 items. The dimensions material centrality, material happiness, and material success 
were each measured with six questions (e.g., "Do you think it is important to own expensive things?", for the full list of items see Opree et al. 2011). Children had to choose from the following response options: (1) "no, not at all," (2) "no, not really," (3) "yes, a little," and (4) "yes, very much." The visual representations of the response options consisted of (1) a very unhappy smiley, (2) a slightly unhappy smiley, (3) a slightly happy smiley, and (4) a very happy smiley. The scores on the 18-item, 6-item, and 3-item MVS-c were computed by calculating the mean score of the corresponding items. The descriptive statistics as well as the reliability coefficients of all three versions of the scale are displayed in part A of Table 1.

Materialism Collage Following Chaplin and John (2007), children were asked to construct a collage about what makes them happy. This method originates from a study by Chaplin and John (2005) into self-brand connections among children between eight and eighteen years old. Later, it was used again by Chaplin in a study into consumption constellations (Chaplin and Lowrey 2010), but this time with younger children as well (i.e., first graders). Because the method proved to be appropriate for measuring materialism in middle childhood as well as similar constructs in early childhood, it was used as a proxy to measure materialism among six- to-eight-year-olds in this study.

Just as in Chaplin and John's (2007) study, children were provided with a set of items from which they could make a selection to compose their personal collage. The whole set included 40 items that were represented by 40 laminated cards which were laid out on a table. Children could incorporate the items into their collage by placing them on a magnetic board in front of them. The children were instructed to select those 10 cards that made them the most happy. The cards were organized in five rows of eight cards, and the cards in each row were related to one theme: There were two rows with material goods, one row with hobbies, one row with people and one row with sports (see Fig. 2). These categories correspond to those used by

Table 1 Descriptive statistics, reliability, and construct validity of the 18-, 6-, and 3-item MVS-c

\begin{tabular}{llll}
\hline & 18 items & 6 items & 3 items \\
\hline A - Descriptive statistics & & & 2.33 \\
Mean & 2.41 & 2.27 & .63 \\
Standard deviation & .49 & .53 & $1.00-4.00$ \\
Observed range & $1.22-3.56$ & $1.17-3.67$ & $.74^{* * * *}$ \\
Correlation with 18-item MVS-c & 1.00 & $.89^{* * *}$ & $.84^{* * * *}$ \\
Correlation with 6-item MVS-c & $.89^{* * *}$ & 1.00 & 1.00 \\
Correlation with 3-item MVS-c & $.74^{* * *}$ & $.84^{* * *}$ & .49 \\
B - Reliability & & & .61 \\
Cronbach's alpha & .85 & & $.23^{*}$ \\
C - Construct validity & & $.20^{* *}$ & -.02 \\
Materialism collage & $.27^{* *}$ & .05 & -.08 \\
Gender & .06 & -.03 & .09 \\
Advertising exposure & .05 & .10 & .01 \\
Requests for products from TV & $.22^{*}$ & -.05 & \\
Life satisfaction & -.03 & & \\
\hline
\end{tabular}

$N=120 .^{*} p<.05,{ }^{* *} p<.01,{ }^{* * *} p<.001$ 


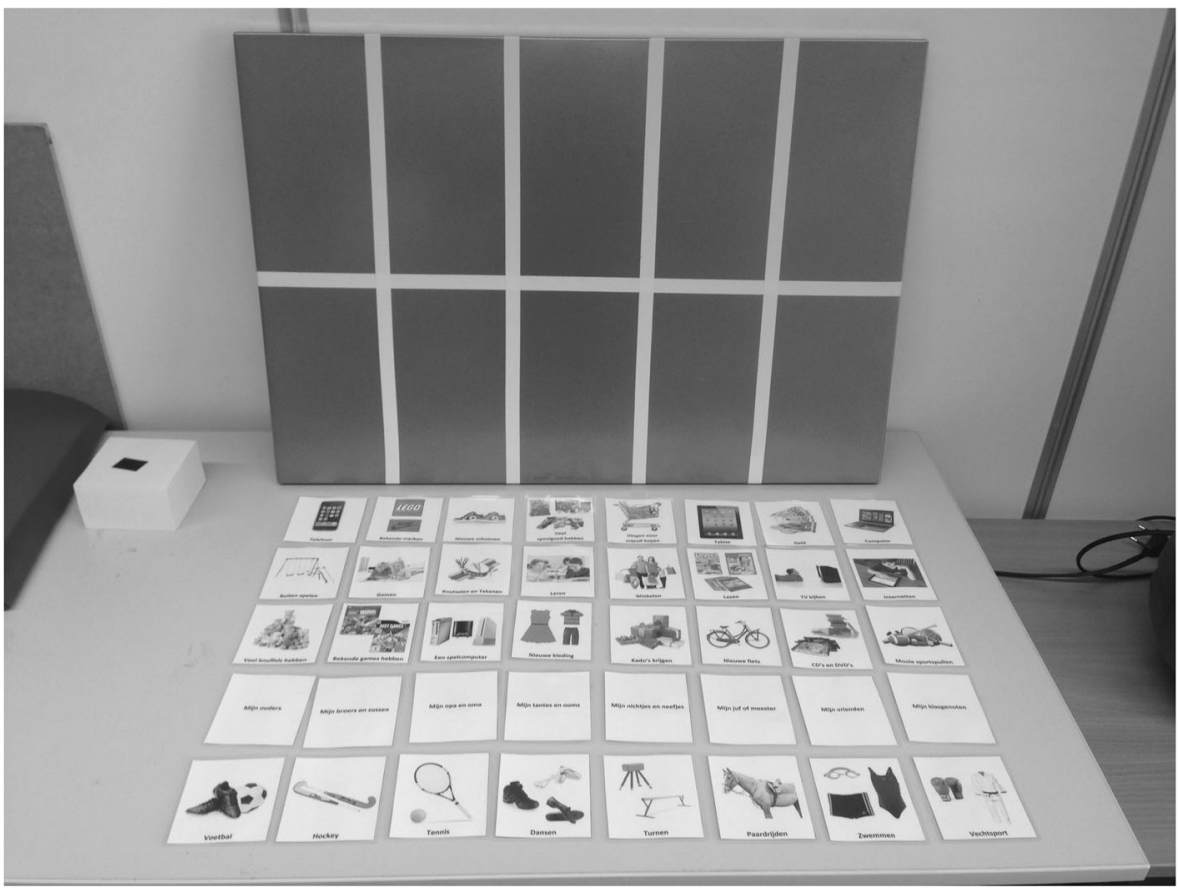

Fig. 2 Setup of collage board and item cards

Chaplin and John (2007). The order of the rows was rotated between children to prevent order effects.

The collage items were carefully selected to ensure that they covered the most important aspects of children's lives (see Fig. 3). The material items were mostly adopted from Chaplin and John (2007). However, some of the original material items, such as a gift certificate and a new purse, were replaced by items depicting technological goods that are currently used by children, such as tablets and game consoles. The category "people" included people who are closest to young children, such as their parents, siblings, teachers, and classmates. Dutch children's most common hobbies and sports were selected for the final two categories (Gemeente Amsterdam, Bureau Onderzoek en Statistiek 2013; Gemeente Haarlemmermeer, Team Onderzoek 2012; Veldacademie 2013). The category "hobbies" included items such as gaming, reading, and drawing. Soccer, tennis, and horse riding are examples of items in the category "sports." Blank cards were available as well, in case children wanted to include something in their collage that was not represented by one of the 40 items. After children had finished their collage, a photograph was taken of the collage. Based on these photographs, the number of material items each child had selected was determined and a sum score was computed $(M=5.52, S D=1.78)$.

Gender As boys and girls are expected to have different levels of materialism, gender was used as a measure to validate the MVS-c. In the analyses, gender was included as a dichotomous variable. Boys were represented by a score of 0 and girls were represented by a score of 1 . 


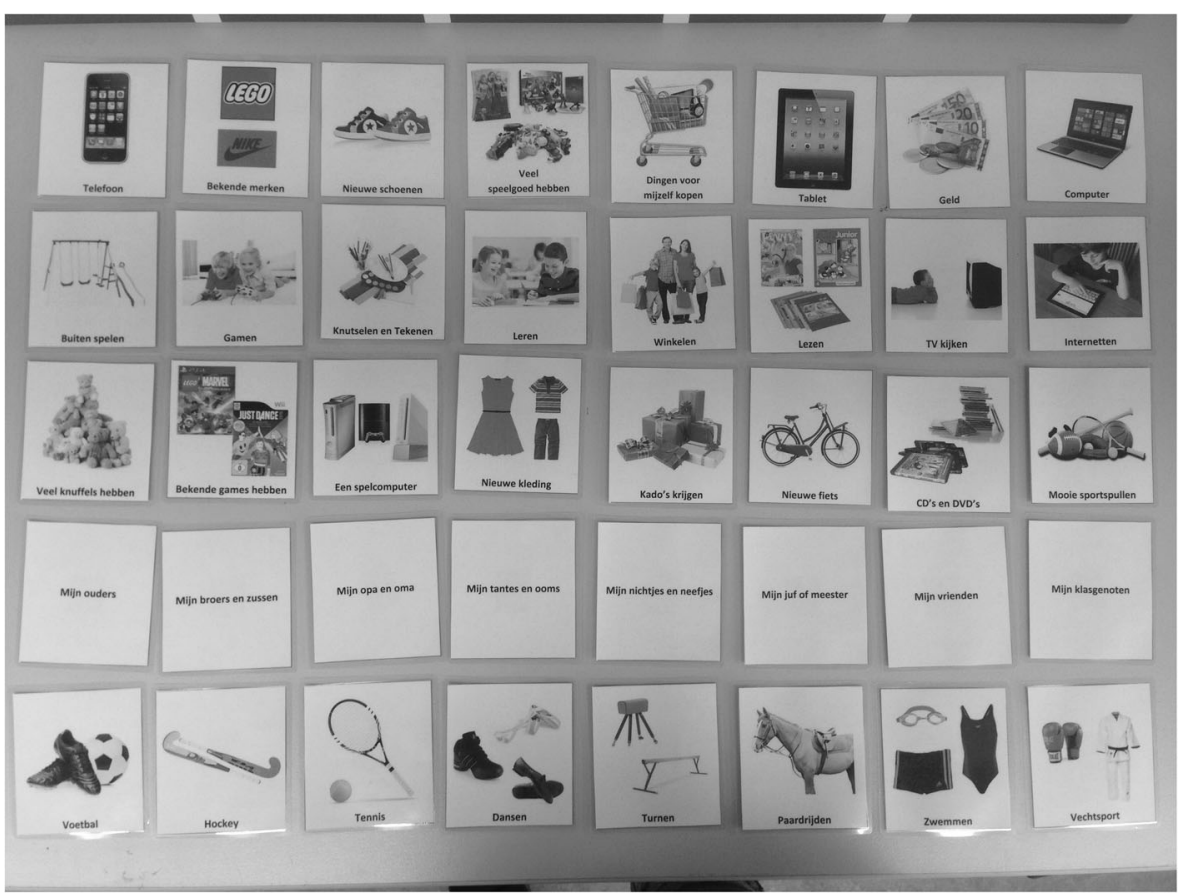

Fig. 3 Photograph of the 40 item cards

Advertising Exposure Children's exposure to advertising was measured through their viewing frequency of several popular network channels. According to Opree et al. (2014), exposure to network channels is a good proxy for advertising exposure performing just as well as the more content-specific measures of advertising exposure, including measures in which children's exposure to networks and/or programs is weighted for advertising density. Data of the Dutch research company Qrius was used to select the network channels (Sikkema 2012). Based on the viewing preferences of six- to nine-year-olds, we selected the two most popular children's channels, the two most popular publicly funded channels, and the two most popular commercial channels. These six channels (i.e., the children's channels Disney XD and Nickelodeon, the public channels NPO1 and NPO3, and the commercial channels RTL4 and SBS6) were included in the items. The children were asked how often they watched these channels, choosing between (1) "never," (2) "sometimes," (3) "often," and (4) "very often." Children's final score for advertising exposure was the mean of the six items $(M=2.03$, $S D=.41)$.

Requests for Products from TV Requests to parents for products seen in television advertising was measured with an instrument adapted from Goldberg et al. (2003). Children were asked: "How often do you ask your parents to buy a product, because you have seen it on TV?". The response options were (1) "never," (2) "sometimes," (3) "often," and (4) "very often" $(M=2.38, S D=.89)$.

Life Satisfaction Children's life satisfaction was measured with a single item of the life satisfaction scale used by Buijzen and Valkenburg (2003b) and Opree et al. (2011). 
The selected item asked children to indicate their overall happiness (i.e., "How happy are you in general?"). The response options corresponding to this question were (1) "not so happy," (2) "a little happy," (3) "happy," and (4) "very happy" ( $M=3.60$, $S D=.63)$.

\section{Results}

\subsection{Multi-Factor Modeling}

Structural equation modeling was used to test the factorial structure of the MVS-c among six- to eight-year-olds. The models were estimated with maximum likelihood estimation in AMOS 21. Maximum likelihood estimation requires multivariate normality (Kline 2011). This assumption was tested in two steps. First, since univariate normality is a precondition for multivariate normality (Kline 2011), we inspected the skewness and kurtosis of each indicator of the MVS-c. Univariate normality is indicated by skewness scores between -2 and +2 and kurtosis scores between -7 and +7 (Kim 2013). Inspecting the univariate distributions of the indicators of the MVS-c revealed only small deviations from normality. Skewness ranged from -.58 to 1.02 , and kurtosis ranged from -1.23 to .42 . Thus, normality of the univariate distributions could be assumed. Second, we inspected Mardia's normalized estimate of multivariate kurtosis. Multivariate normality can be assumed when Mardia's coefficient lies below 5.00 (Byrne 2010). Mardia's coefficient was 4.46 and thus below the critical threshold.

Model fit was evaluated using the normed Chi-square (i.e., $\chi^{2}$ divided by degrees of freedom), the Comparative Fit Index (CFI), and the Root Mean Square Error of Approximation (RMSEA) and its p-close. A normed Chi-square value below 2.00 is generally considered to be indicative of a good model fit (Hooper et al. 2008). CFI values larger than .95 and RMSEA values smaller than .05 with a non-significant p-close indicate good model fit (Byrne 2010). CFI values between .90 and .95 and RMSEA values between .05 and .08 are considered acceptable too (Byrne 2010).

Following the method of Opree et al. (2011) in their development of the original MVS-c, an oblique factor model and a nested factors model were tested prior to testing the higher-order model in Fig. 1 (see Gignac 2007). The oblique factor model included three correlated factors representing material centrality, material happiness, and material success. The oblique factor model indicates whether each item has a significant loading on its designated factor (i.e., on material centrality, material happiness, or material success). The nested factor model included the same three factors, but this time the factors were uncorrelated and a general factor for overall materialism was included. The nested model shows whether each item, in addition to leading on its designated factor, also loads on overall materialism. Finally, the higher-order model from Fig. 1 reveals whether the item loadings on overall materialism can be explained through their loadings on their respective first order-factor (i.e., material centrality, material happiness, and material success being indicators of overall materialism). 
Similar to the analyses of Opree et al. (2011), shared measurement error was controlled for by allowing error terms for items with a similar subject to correlate (e.g., "Do you think it's important to own a lot of money?" and "Does having a lot of money make you happy?"). In order to identify the models, the factor loading of the first indicator of each subscale was fixed to 1 . In addition, the variance of the secondorder factor material values was fixed to 1 in the higher-order model (Kline 2011).

The oblique factor model, which included the 18 items of the MVS-c as manifest indicators and material centrality, material happiness, and material success as first-order latent factors was tested first. The model had an acceptable fit: $\chi^{2}$ (130, $n=120)=171.84, p<.01 ; \chi^{2} / \mathrm{df}=1.32 ; \mathrm{CFI}=.92 ; \mathrm{RMSEA}=.05, p$-close $=.42$. All items turned out to have a significant, positive factor loading on their designated factor $(p<.001)$, except for the sixth item for material happiness. This suggests that the three first-order factors are well defined (Gignac 2007). The nested model also resulted in an acceptable fit: $\chi^{2}(115, n=120)=151.59, p<.05 ; \chi^{2} / \mathrm{df}=1.32 ; \mathrm{CFI}=.93$; RMSEA $=.05, p$-close $=.44$. When ignoring non-significant factor loadings, all items appeared to have unidirectional loadings on their designated factor. More importantly, all items, except for the sixth item of material happiness, showed a significant and positive factor loading on the general material values factor $(p<.01)$. This reveals that all items can be used as indicators for overall materialism.

Lastly, the higher-order model in Fig. 1 was tested to verify the second-order structure of material values among children from six to eight years old. A secondorder latent factor was added for overall material values, which enabled us to determine the factor loadings of the first-order factors on general material values. The model fit of the second-order model was identical to the fit of the oblique model $\left(\chi^{2}(130, n=120)=171.84, p<.01 ; \chi^{2} / \mathrm{df}=1.32 ; \mathrm{CFI}=.92 ; \mathrm{RMSEA}=.05, p\right.$-close $=.42$ ), as the models are equivalent. The first-order factors all had high, positive loadings on the second-order factor $\left(\beta_{\text {centrality }}=.87, \beta_{\text {happiness }}=.92, \beta_{\text {success }}=.78\right.$, $p<.001)$. This indicates that the factorial structure among this sample is similar to that of the original MVS-c among 8- to 11-year-olds and it corroborates the idea that material values in children are composed of material centrality, material happiness, and material success.

We followed the conventional style of reporting on model fit and - in addition to the normed Chi-square, the CFI, RMSEA, and p-close - also provided the results of the three models' chi-square significance tests. Non-significant chi-square tests are an indication of acceptable fit. If a chi-square test is significant, however, the model's correlation residuals (i.e., the difference between the sample correlations and the model-implied correlations) or standardized covariance residuals should be inspected to assess whether substantial misspecifications occurred. "Too many" large residuals are indicative of misspecifications (Kline 2011). The standardized residual covariances provided by AMOS 23 can be interpreted as z-values (see Kline 2011, p. 171): Values below -1.96 and values over 1.96 are regarded as significant/ large. In each model, only one out of 153 standardized residual covariances was substantial (with a value of -2.022 in the oblique and the second-order factor model, and a value of 1.982 in the orthogonal model). Because the majority of the fit measures indicated that the fit of the models was acceptable and because the analysis of the residual covariances showed that there were no major misspecifications, no model modifications were initiated. 


\subsection{Reliability}

Part of validating the MVS-c among six- to eight-year-olds was testing the reliability of the scale among this age group. Reliability of the MVS-c was assessed by means of Cronbach's alpha and reliability coefficients were interpreted according to DeVellis' (2003) guidelines. The reliability coefficients of the 18-, 6-, and 3-item MVS-c are displayed in part B of Table 1 . The full 18-item scale yielded very good reliability $(\alpha=.85)$. The shorter 6 - and 3-item version demonstrated lower reliability coefficients. The reliability of the 6 -item scale was just acceptable $(\alpha=.61)$, however, the reliability of the 3-item scale was unacceptable (i.e., <.60; $\alpha=.49$ ) (DeVellis 2003). In sum, except for the 3-item scale, the scales had adequate reliability, reflecting sufficient internal consistency within the different versions of the MVS-c among six- to eightyear-olds.

\subsection{Construct Validity}

Another important part of validating the MVS-c was testing the construct validity. To do this, the scales were correlated with Chaplin and John's (2007) collage measure for materialism, gender, advertising exposure, requests for products from TV, and life satisfaction. The results for the 18-, 6-, and 3-item MVS-c are displayed in part C of Table 1. As expected, the MVS-c was significantly correlated to children's collages, which served as a different measure for materialism $\left(r_{18 \text {-item }}=.27, p<.01 ; r_{6-i t e m}=.20\right.$, $\left.p<.05 ; r_{3 \text {-item }}=.23, p<.05\right)$. Also, the 18 -item MVS-c was significantly correlated to children's requests for products from TV $\left(r_{18-i t e m}=.22, p<.05\right)$, whereas the shorter versions of the MVS-c were not. Gender, advertising exposure and life satisfaction did not correlate with the MVS-c, or a shorter version of the scale.

Altogether, the results only partially support construct validity of the MVS-c among this age group. However, the expected relationships between the MVS-c and the validation measures were based on relationships with materialism found among older children (see section 1.3). We tested the correlations between the collage measure for materialism and the validation measures too, in order to set a new benchmark. The results appeared to be very similar. No significant correlations were found between the materialism collage and children's advertising exposure, requests for products from TV or life satisfaction. Only gender was significantly correlated to the collage $(r=-.34, p<.001)$. The negative correlation implies that girls, who were represented by a score of 1 , tended to score lower on the materialism collage. This result might be attributable to the fact that some collage items were more popular among boys than girls and vice versa. Fisher's exact tests showed that boys were more likely to select the cards that represented popular brands, a tablet, a computer, gaming, having popular games, having a game console, nice sports equipment, soccer, and martial arts $(p<.05)$, whereas girls were more likely to select the cards that represented playing outside, crafting and drawing, shopping, reading, having lots of stuffed animals, new clothes, my parents, dancing, gymnastics, and horse riding $(p<.05)$. It seems that the boys' popular collage items were often related to technology and, as a consequence, included more material items. The popular items among girls were mainly hobbies, which included more non-material items. Considering the above, generally the 
same pattern of correlations was found for the scale and the collage, supporting construct validity of the MVS-c.

\section{Discussion}

The aim of this study was to validate the Material Values Scale for children by Opree et al. (2011) among a younger age group. To do so, the scale was administered to 125 children between six and eight years old in a structured interview. The presumed second-order structure of the scale was tested with structural equation modeling and the reliability and validity of the scale and its shorter versions were examined. The results showed that the factorial structure of the MVS-c is confirmed for children from six to eight years old. Moreover, it was found that the MVS-c can be used to measure the material values of six- to eight-year-olds in a time-efficient manner.

An important finding of this study is that children's material values are indeed a second-order construct with material centrality, material happiness, and material success as underlying constructs. In contrast to John's (1999) theory this demonstrates that, even at the age of six, children's material values are well-evolved. According to John (1999), the material values of children at this age are only based on a perceptual dimension and get more nuanced during elementary school. Our study, however, showed that material possessions do not only take a central place in young children's lives, but are also associated with happiness and success. Young children's ability to draw these associations is in line with the finding of Chan (2003) that they already have an understanding of the value of possessions based on social significance, and with previous research which has shown that children begin to make inferences about people based on the products they use when they are between six and eight years old (Belk et al. 1982; Mayer and Belk 1982).

Another important finding is that not all three versions of the MVS-c appeared to be suitable for the use among younger children. The results regarding the reliability of the scale demonstrate that the 18-item scale and the 6-item scale are reliable and therefore appropriate for use among children in early childhood. The 3-item scale, in contrast, had a very low reliability (i.e., $\alpha<.60$; see DeVellis 2003), which makes it inappropriate to use. The fact that the 6-item version of the scale did prove to be useful among this age group, means that materialism in young children can now be measured much more time-efficiently than by means of a collage task. The 6-item MVS-c might be of great use in further research into the causes and consequences of childhood materialism.

This study found only partial support for construct validity of the MVS-c among a younger age group. Construct validity of the scale was established through the correlation between children's MVS-c score and their score on the collage measure for materialism, which was the most important validation measure. The correlation between the MVS-c and the materialism collage was also not as strong as expected. This finding may be attributed to the fact that, contrary to the scale, the collage measure is unable to capture all three dimensions of materialism. In fact, in the collage task, the children were instructed to select those items that made them most happy (with most referring to importance and thus material centrality, and happy to material happiness). Material success (i.e., the degree to which children assess the success of others in terms 
of possessions) is less likely to be assessed with the collage measure, because it is not referred to in the instruction. Accordingly, we found that the collage measure of materialism was significantly associated with material centrality and material happiness, but not with material success. This may have attenuated the correlation between the collage measure and the MVS-c. That being said, approaching .30, the correlation of .27 can be still considered moderate according to Cohen's (1988) conventions. Irrespective, because establishing a scale's validity is a cumulative endeavor, future studies could further investigate the validity of the MVS-c among younger children by assessing how the scale is associated to related concepts, such as narcissism and entitlement.

As expected, children's MVS-c scores were related to the amount of purchase requests to parents for products they have seen on TV. In contrast, no significant correlations were found between the MVS-c and children's gender, advertising exposure, and life satisfaction. The cross-sectional nature of the data may be one of the reasons for these unexpected findings. Assuming their relations are causal (e.g., advertising exposure causing materialism) different results may be found in a longitudinal study. A second reason for not finding some of the expected relations could be that the relations are not yet fully present among six- to eight-year-olds. Finding a similar pattern in the correlations for the MVS-c and the collage measure for materialism supports this thought. Because the validation measures were based on relationships found among older children and as there is still little research on materialism in early childhood, we do not exactly know yet when the relations between materialism and gender, advertising exposure, and life satisfaction begin to emerge.

When it comes to life satisfaction, there may be a third explanation for not finding a correlation to the MVS-c. Research has shown that low life satisfaction can lead to higher levels of materialism but that being more materialistic does not decrease life satisfaction in children (Opree et al. 2012). It is thought that children who are dissatisfied with their lives may seek happiness and fulfillment in material possessions. However, a strong ceiling effect for life satisfaction was found in this study, indicating that the participating children were all very happy and satisfied with their life. Therefore, they may not need materialism as a coping mechanism.

By validating the MVS-c among six- to eight-year-olds the current study contributes to our knowledge in this area of research in three ways. Firstly, with the 18-item MVS-c and its 6-item shorter version there now is an appropriate and time-efficient way to measure materialism among children younger than eight years old. Secondly, we are now able to compare children's material values among different age groups. The MVS-c, which was originally developed for children between eight and eleven years old, has now also been validated for the use among six- to eight-year-olds. Lastly, because the MVS-c can be used among sixto eleven-year-old children, the development of children's material values can be studied over a longer period of time. This will provide new insights into the causes and consequences of materialism across the life span.

Altogether the validation of the MVS-c among six- to eight-year-olds provides new opportunities to study young children's material values. It offers the possibility to further research the effect of advertising exposure on materialism as well as other unintended effects of advertising among young children. The findings of this study suggest that children below eight are able to understand the symbolic meaning of 
material possessions. Additional research is needed to find out when children start to get an understanding of consumption symbolism. It could for instance be that today's children learn about this at a much younger age than children did 20 years ago, because they are being targeted and seen as a consumer from a very young age (Mau et al. 2014). The current study is an important step on the way to finding that out.

\section{Compliance with Ethical Standards}

Conflict of Interest The authors declare that they have no conflict of interest.

Open Access This article is distributed under the terms of the Creative Commons Attribution 4.0 International License (http://creativecommons.org/licenses/by/4.0/), which permits unrestricted use, distribution, and reproduction in any medium, provided you give appropriate credit to the original author(s) and the source, provide a link to the Creative Commons license, and indicate if changes were made.

\section{References}

Belk, R. W., Bahn, K. D., \& Mayer, R. N. (1982). Developmental recognition of consumption symbolism. Journal of Consumer Research, 9(1), 4-17.

Borgers, N., De Leeuw, E., \& Hox, J. (2000). Children as respondents in survey research: cognitive development and response quality. Bulletin de Methodologie Sociologique, 66(1), 60-75.

Borgers, N., Sikkel, D., \& Hox, J. (2004). Response effects in surveys on children and adolescents: the effect of number of response options, negative wording, and neutral mid-point. Quality and Quantity, $38(1), 17-33$.

Bottomley, P. A., Nairn, A., Kasser, T., Ferguson, Y. L., \& Ormrod, J. (2010). Measuring childhood materialism: refining and validating Schor's consumer involvement scale. Psychology \& Marketing, 27(7), 717-739.

Buijzen, M., \& Valkenburg, P. M. (2003a). The effects of television advertising on materialism, parent-child conflict, and unhappiness: a review of research. Journal of Applied Developmental Psychology, 24(4), 437-456.

Buijzen, M., \& Valkenburg, P. M. (2003b). The unintended effects of television advertising. A parent-child survey. Communication Research, 30(5), 483-503.

Buijzen, M., \& Valkenburg, P. M. (2005). Parental mediation of undesired advertising effects. Journal of Broadcasting \& Electronic Media, 49(2), 153-165.

Buijzen, M., van Reijmersdal, E. A., \& Owen, L. H. (2010). Introducing the PCMC model: an investigative framework for young people's processing of commercial media content. Communication Theory, 20(4), $427-450$.

Byrne, B. M. (2010). Structural equation modeling with AMOS: Basic concepts, applications, and programming (2nd edition). New York, NY: Routledge.

Chan, K. (2003). Materialism among Chinese children in Hong Kong. Young Consumers, 4(4), 47-61.

Chaplin, L. N., \& John, D. R. (2005). The development of self-brand connections in children and adolescents. Journal of Consumer Research, 32(1), 119-129.

Chaplin, L. N., \& John, D. R. (2007). Growing up in a material world: age differences in materialism in children and adolescents. Journal of Consumer Research, 34(4), 480-493.

Chaplin, L. N., \& Lowrey, T. M. (2010). The development of consumer-based consumption constellations in children. Journal of Consumer Research, 36(5), 757-777.

Cohen. (1988). Statistical power analysis for the behavioral sciences. Hillsdale: Lawrence Erlbaum.

DeVellis, R. F. (2003). Scale development. Theory and applications. Thousand Oaks: Sage.

Gemeente Amsterdam, Bureau Onderzoek en Statistiek. (2013). Sportmonitor 2013. Inzicht in het sportgedrag van Amsterdammers [Sports monitor 2013. The sports habits of the citizens of Amsterdam]. Amsterdam: Gemeente Amsterdam. 
Gemeente Haarlemmermeer, Team Onderzoek. (2012). Het sportlandschap van Haarlemmermeer 2 [The sports landscape in Haarlemmermeer]. Haarlemmermeer: Gemeente Haarlemmermeer.

Gignac, G. E. (2007). Multi-factor modeling in individual differences research: some recommendations and suggestions. Personality and Individual Differences, 42(1), 37-48.

Goldberg, M. E., \& Gorn, G. J. (1978). Some unintended consequences of TV advertising to children. Journal of Consumer Research, 5(1), 22-29.

Goldberg, M. E., Gorn, G. J., Peracchio, L. A., \& Bamossy, G. (2003). Understanding materialism among youth. Journal of Consumer Psychology, 13(3), 278-288.

Greig, A. D., Taylor, M. J., \& MacKay, T. (2007). Doing research with children. London: Sage.

Hooper, D., Coughlan, J., \& Mullen, M. (2008). Structural equation modelling: Guidelines for determining model fit. Electronic Journal of Business Research Methods, 6(1), 53-60.

John, D. R. (1999). Consumer socialization of children: a retrospective look at twenty-five years of research. Journal of Consumer Research, 26(3), 183-213.

Kasser, T. (2005). Frugality, generosity, and materialism in children and adolescents. In K. Anderson Moore \& L. H. Lippman (Eds.), What do children need to flourish? Conceptualizing and measuring indicators of positive development (pp. 357-373). New York: Springer US.

Kasser, T., \& Linn, S. (2016). Growing up under corporate capitalism: the problem of marketing to children, with suggestions for policy solutions. Social Issues and Policy Review, 10(1), 122-150.

Kim, H.-Y. (2013). Statistical notes for clinical researchers: assessing normal distribution (2) using skewness and kurtosis. Restorative Dentistry \& Endodontics, 38(1), 52.

Kline, R. B. (2008). Becoming a behavioral science researcher: a guide to producing research that matters. New York: The Guilford Press.

Kline, R. B. (2011). Principles and practice of structural equation modeling (3rd ed.). New York: The Guilford Press.

Mau, G., Schramm-Klein, H., \& Reisch, L. (2014). Consumer socialization, buying decisions, and consumer behaviour in children: introduction to the special issue. Journal of Consumer Policy, 37(2), 155-160.

Mayer, R. N., \& Belk, R. (1982). Acquisition of consumption stereotypes by children. Journal of Consumer Affairs, 16(2), 307-321.

Noar, S. M. (2003). The role of structural equation modeling in scale development. Structural Equation Modeling, 10(4), 622-647.

Opree, S. J., Buijzen, M., van Reijmersdal, E. A., \& Valkenburg, P. M. (2011). Development and validation of the material values scale for children (MVS-c). Personality and Individual Differences, 51(8), 963-968.

Opree, S. J., Buijzen, M., \& Valkenburg, P. M. (2012). Lower life satisfaction related to materialism in children frequently exposed to advertising. Pediatrics, 130(3), e486-e491.

Opree, S. J., Buijzen, M., \& van Reijmersdal, E. A. (2014). Children's advertising exposure: assessing the reliability and validity of survey measures. Paper presented at the 6th international conference on multidisciplinary perspectives on child and teen consumption. Edinburgh: United Kingdom.

Preston, C. (2004). Children's advertising: the ethics of economic socialisation. International Journal of Consumer Studies, 28(4), 364-370.

Reynolds-Keefer, L., Johnson, R., Dickenson, T., \& McFadden, L. (2009). Validity issues in the use of pictorial Likert scales. Studies in Learning, Evaluation, Innovation and Development, 6(3), 15-24.

Richins, M. L., \& Dawson, S. (1992). A consumer values orientation for materialism and its measurement: scale development and validation. Journal of Consumer Research, 19(3), 303-316.

Sikkema, P. (Ed.). (2012). Kinderen en jongeren. Positieve kracht [children and youth. Positive strength]. Amsterdam: Qrius.

Valkenburg, P. (2008). Beeldschermkinderen: Theorieën over kind en media. [screen-kids: theories about children and media]. Amsterdam: Boom.

Vandana, \& Lenka, U. (2014). A review on the role of media in increasing materialism among children. Procedia-Social and Behavioral Sciences, 133, 456-464.

Veldacademie. (2013). Behoefteonderzoek talentontwikkeling. Mogelijkheden voor talentontwikkeling in de deelgemeente Prins Alexander [Investigating needs for talent development. Opportunities in the Prins Alexander sub-community]. Rotterdam: Veldacademie http://www.veldacademie. $\mathrm{nl} /$ projecten/behoefteonderzoek-talentontwikkeling. Accessed 30 May 2016. 